\title{
Unspecified Cells to Total Cell Ratio Measurement
}

National Cancer Institute

\section{Source}

National Cancer Institute. Unspecified Cells to Total Cell Ratio Measurement. NCI

Thesaurus. Code C114225.

The determination of the ratio of the cells not otherwise identified or specified compared to total cells in a sample. The measurement may be expressed as a ratio or percentage. 